\title{
Eastern Arabian Sea Climate Change during Mid-Pleistocene Transition
}

\section{SHUBHAM TRIPATHI}

National Centre for Polar and Ocean Research

Presenting Author: shubham@ncpor.res.in

Most of the studies from the eastern Arabian Sea spanning the Mid-Pleistocene Transition (MPT) are qualitative. Here, we present the high-resolution record of productivity, denitrification, provenance, oceanic temperature and salinity variability from MIS 18 to MIS 28 spanning a major part of MPT. The productivity and denitrification was higher during the warmer periods of the MPT accompanied by weaker ventilation. We also compared our record to the productivity and denitrification variability from the Western Arabian Sea. We found a synchronous variability between the two regions during MPT. We carried out the paired measurement of $\mathrm{Mg} / \mathrm{Ca}$ and $\delta^{18} \mathrm{O}$ of $G$. sacculifer. Our record shows that the MLT varied from $28{ }^{\circ} \mathrm{C}$ to as low as $\sim 19{ }^{\circ} \mathrm{C}$ with a mean value of $\sim 23{ }^{\circ} \mathrm{C}$. The $\mathrm{d}^{18} \mathrm{O}_{\mathrm{sw}}$ and salinity range from $\sim 39$ to $\sim 32$ units with a mean value of $\sim 36$ units. At the study site, low MLT and high salinity occur during the monsoon as shown by the present day climatology. We find high salinity during the warmer periods (MIS 27, 25, 21 and 19) implying intense monsoon. The salinity and temperature record generated shows that the monsoon intensified during the warmer periods of MPT. We also examined our data and looked for the possible linkage of SAsM to the forcing factors like solar insolation at $15^{\circ} \mathrm{S}\left(\mathrm{I} 15^{\circ} \mathrm{S}\right)$ and precession during MPT. We visibly examine the relationship between the $115^{\circ} \mathrm{S}$ and the $\delta^{18} \mathrm{O}_{\text {sac }}$ variability. We saw a good match of $115^{\circ} \mathrm{S}$ with $\mathrm{d}^{18} \mathrm{O}_{\text {sac }}$, which corroborates earlier study of upper-ocean stratification from the Southern Indian Ocean. It supports a robust sensitivity to warming in the Southern Hemisphere. The continuous wavelet transform reveals that the $\sim 24 \mathrm{kyr}$ periodicity dominates from $0.97 \mathrm{Ma}$ to $0.85 \mathrm{Ma}$. The same periodicity is observed during $\sim 0.79 \mathrm{Ma}$ to $\sim 0.77 \mathrm{Ma}$. The significance of internal forcing might get reflected by small scale periodicities of $\sim 7 \mathrm{kyr}$ and $\sim 15$ kyr. 